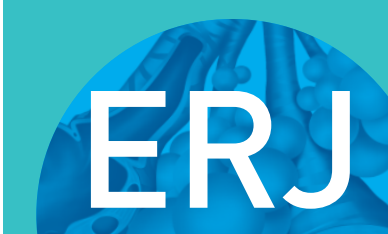

open research 5

\section{A syndromic approach to assess diagnosis and management of patients presenting with respiratory symptoms to healthcare facilities in Vietnam}

\author{
Wan-Chun Huang ${ }^{1,2,3}$, Gregory J. Fox ${ }^{1,4}$, Ngoc Yen Pham ${ }^{1}$, Thu Anh Nguyen', \\ Van Giap Vu ${ }^{5}$, Quy Chau Ngo ${ }^{5}$, Viet Nhung Nguyen ${ }^{6}$, Stephen $\mathrm{Jan}^{7}$, Joel Negin ${ }^{8}$, \\ Thi Tuyet Lan Le $e^{9}$ and Guy B. Marks (1) ${ }^{1,2}$
}

\begin{abstract}
Affiliations: ${ }^{1}$ Woolcock Institute of Medical Research, Hanoi, Vietnam. ${ }^{2}$ South Western Sydney Clinical School, University of New South Wales, Sydney, Australia. ${ }^{3}$ Division of Thoracic Medicine, Dept of Internal Medicine, Shuang Ho Hospital, Taipei Medical University, Taipei, Taiwan. ${ }^{4}$ Faculty of Medicine and Health, University of Sydney, Sydney, Australia. ${ }^{5}$ Respiratory Center, Bach Mai Hospital, Hanoi, Vietnam. ${ }^{6}$ National Tuberculosis Control Program of Vietnam, Hanoi, Vietnam. ${ }^{7}$ Health Economics and Process Evaluation Program, George Institute for Global Health, Sydney, Australia. ${ }^{8}$ School of Public Health, University of Sydney, Sydney, Australia. ${ }^{9}$ Society of Asthma and Allergy \& Clinical Immunology, Ho Chi Minh City, Vietnam.
\end{abstract}

Correspondence: Guy B. Marks, South Western Sydney Clinical School, The University of New South Wales, NSW, 2170, Australia. E-mail: g.marks@unsw.edu.au

\section{ABSTRACT}

Background: The aim of the study was to establish syndromic diagnoses in patients presenting with respiratory symptoms to healthcare facilities in Vietnam and to compare the diagnoses with facility-level clinical diagnoses and treatment decisions.

Methods: A representative sample of patients aged $\geqslant 5$ years, presenting with dyspnoea, cough, wheezing, and/or chest tightness to healthcare facilities in four provinces of Vietnam were systematically evaluated. Eight common syndromes were defined using data obtained.

Results: We enrolled 977 subjects at 39 facilities. We identified fixed airflow limitation (FAL) in 198 (20.3\%) patients and reversible airflow limitation (RAL) in $26(2.7 \%)$ patients. Patients meeting the criteria for upper respiratory tract infection (URTI) alone constituted $160(16.4 \%)$ patients and 470 (48.1\%) did not meet the criteria for any of the syndromes. Less than half of patients with FAL were given long-acting bronchodilators. A minority of patients with either RAL or FAL with eosinophilia were prescribed inhaled corticosteroids. Antibiotics were given to more than half of all patients, even among those with URTI alone. Conclusion: This study identified a substantial discordance between prescribed treatment, clinician diagnosis and a standardised syndromic diagnosis among patients presenting with respiratory symptoms. Increased access to spirometry and implementation of locally relevant syndromic approaches to management may help to improve patient care in resource-limited settings.

@ERSpublications

This study identified discordance between a standardised syndromic diagnosis of respiratory diseases and the diagnosis reached within the Vietnamese health system. Implementing a syndromic approach to case management might help to improve patient care. https://bit.ly/ 36oJORg

Cite this article as: Huang W-C, Fox GJ, Pham NY, et al. A syndromic approach to assess diagnosis and management of patients presenting with respiratory symptoms to healthcare facilities in Vietnam. ERJ Open Res 2021; 7: 00572-2020 [https://doi.org/10.1183/23120541.00572-2020].

This article has supplementary material available from openres.ersjournals.com.

Received: 12 Aug 2020 | Accepted: 5 Nov 2020

Copyright OERS 2021. This version is distributed under the terms of the Creative Commons Attribution NonCommercial Licence 4.0. For commercial reproduction rights and permissions contact permissions@ersnet.org 


\section{Introduction}

Respiratory diseases are common reasons for presentation to healthcare facilities worldwide and impose a large burden upon the health system $[1,2]$. The prevalence of chronic respiratory diseases, including COPD and asthma, has been rising globally, with an increase in deaths due to these diseases [3]. Lower respiratory tract infection (LRTI) and tuberculosis also remain major causes of mortality, especially in lowand middle-income countries (LMICs) [2, 4].

In many settings, the diagnosis and management of chronic respiratory diseases remains suboptimal. Incorrect diagnostic pathways contribute to inappropriate treatment decisions [5], and poor outcomes. Many patients who are labelled as having COPD, or its related entities emphysema or chronic bronchitis, lack demonstrable airflow obstruction on spirometry [6]. On the other hand, population-based surveys in diverse locations demonstrate that many people with airflow limitation measured on spirometry have never been formally diagnosed with COPD or asthma $[7,8]$.

A correct diagnostic label should lead to the initiation of treatment that is beneficial to patients. For example, some patients with COPD will benefit from treatment with inhaled corticosteroids, while others do not $[9,10]$. This latter group includes some patients who develop excess pneumonia as a result of treatment with inhaled corticosteroids $[11,12]$. There is evidence that markers reflecting underlying eosinophilic inflammation are useful for identifying those likely to benefit from inhaled corticosteroids [9]. Other therapies are effective for selected patient groups: bronchodilators will most benefit patients with respiratory symptoms who have airflow limitation [13, 14], while antimicrobial agents will be beneficial when bacterial infection is present. Accurate diagnostic decision-making is essential to ensure that the right treatment is given to the right patient.

Inappropriate treatment decisions for respiratory diseases are common in many healthcare systems [15-17]. Strategies have been developed to improve decision-making for respiratory diseases [18-20], including the World Health Organization-recommended "Practical Approach to Lung Health" that aims to improve the quality of care for patients with respiratory symptoms at first-level health facilities [1]. This symptom-based approach does not require extensive diagnostic testing, and has been shown to be feasible in resource-limited settings [21-24]. Once respiratory syndromes have been correctly identified, optimal therapeutic approaches can be adopted [21,25].

In Vietnam, the clinical characteristics of patients presenting with respiratory symptoms to different levels of healthcare have not been well characterised. Similarly, the correlation between diagnosis and treatment for respiratory diseases is poorly understood. Given the incomplete implementation of evidence-based strategies shown in previous studies [16, 26, 27], we hypothesised that a simple syndromic approach can be used to assess the quality of care in a healthcare system and may improve patient care.

The aim of this study was to establish syndromic diagnoses for a representative sample of patients presenting with respiratory symptoms to healthcare facilities in Vietnam using a simple, standardised diagnostic approach and to compare this syndromic diagnosis with the clinical diagnosis and treatment decisions made by local healthcare workers.

\section{Methods}

\section{Study design}

We implemented an observational study with a baseline survey, diagnostic tests and a follow-up assessment at 4 weeks.

\section{Study setting}

The study was conducted in four provinces of Vietnam, a middle-income country in Southeast Asia with a population of 96 million people. The four provinces comprised two in the north (Hanoi Capital and Thanh Hoa Province) and two in the south (Ho Chi Minh City and Ca Mau Province).

Patients were recruited from healthcare facilities at all four levels of the Vietnamese health system: central (national) hospitals, provincial hospitals, district hospitals and commune health centres.

\section{Sampling of study sites and participants}

Major central and provincial hospitals in each province were included. In addition, four district hospitals were selected by random sampling within each of the four provinces. Two commune health centres from each selected district were also chosen by random sampling. The probability of each facility being chosen was proportional to the populations of the districts and communes within which the healthcare facilities were located. Within each central and provincial hospital, departments in which patients with respiratory diseases were routinely managed were included. At district hospitals, patients were recruited at outpatient clinics. 
Recruitment commenced at each site on a randomly selected day of the week. Consecutive patients, aged 5 years old and above, who attended the study sites for clinical assessment and all inpatients in participating wards during the recruitment period were listed in an enumeration logbook. The age, sex, current respiratory symptoms, and smoking status of all patients were recorded.

Sample size was calculated from estimating the prevalence of COPD in different levels of facilities. We expected the prevalence of COPD among patients seeking healthcare with respiratory symptoms would be $15 \%$. With a precision of $5 \%$ and an $\alpha$ of 0.05 , assuming approximately $20 \%$ loss to follow-up at the 4-week visit, we aimed at recruiting 250 individuals for follow-up per category.

\section{Eligibility and consent}

Enumerated patients who met the eligible criteria were selected at random to participate in the study. Patients aged 5 years old and above presenting to the facility with at least one respiratory symptom (dyspnoea, cough, wheezing, and/or chest tightness) that occurred within the previous $24 \mathrm{~h}$ were eligible. Patients who were unable to complete the survey due to communication difficulties, who were resident in another province, or who were known to be pregnant were ineligible. For outpatients, the sampling fraction was calculated before the commencement of recruitment, based upon the number of individuals who could be seen by study staff within 1 day, as a proportion of the average number of daily patients attending the clinic over the preceding 6 month period. Recruitment of patients continued until the recruitment target was reached at each site.

In order to assess potential selection bias, patients who declined to participate were asked to complete a brief "minimal data questionnaire" that included their demographic details.

Eligible participants were asked to give written informed consent. Participants completing the minimal data questionnaire were asked to provide verbal consent only.

\section{Study measurements}

Data collected from consenting participants during the baseline survey included age, sex, body weight, body height, presenting symptoms, highest level of education attainment, current occupation, smoking habit, comorbidities, and the Common Cold Questionnaire [28]. Anteroposterior chest radiography and full blood count with white blood cell differential count were also obtained. Patients aged 50 years or more with dyspnoea had blood collected for brain natriuretic peptide (BNP) or N-terminal pro-BNP (NT-proBNP). The cut-off points for elevated BNP, NT-proBNT, neutrophilia, and eosinophilia are shown in table 1. Patients with cough for more than 2 weeks had their sputum tested for Mycobacterium tuberculosis using GeneXpert MTB/RIF (Cepheid, Sunnyvale, CA, USA). Diagnoses made and treatment administered by the treating clinician were also recorded.

Trained technicians performed spirometry using EasyOne Air spirometer (ndd Medizintechnik) according to American Thoracic Society/European Respiratory Society guidelines [34]. Participants performed the procedure with no salbutamol administered at the baseline visit. At the 4-week visit, measurements were made before and $15 \mathrm{~min}$ after administration of $400 \mu \mathrm{g}$ of salbutamol via a metered-dose inhaler with spacer.

An external reviewer independent from the study interpreted the results of spirometry following a consensus statement for office spirometry from the National Lung Health Education Program [35]. Spirometry results with a quality of $\mathrm{A}$ to $\mathrm{C}$ were considered valid and included in the analysis. We excluded results with a quality of D and F (criteria shown in supplementary table S1).

Chest radiographs performed at the facilities were reviewed independently by two experienced respiratory physicians. The readers recorded the presence of airspace opacity, cardiomegaly, and pulmonary venous hypertension based on the definitions in supplementary table S2. Disagreements in interpretation between the two physicians were resolved by consensus discussion. A third respiratory physician adjudicated where consensus could not be reached.

Healthcare workers did not have access to the above diagnostic tests performed for this study if the tests were not performed as a part of their clinical investigation.

\section{Syndromic diagnoses}

Eight syndromes were defined, a priori, using data from the survey and the diagnostic test described above (table 1). We used the Global Lung Function Initiative 2012 reference value to determine the lower limit of normal [36]. For each syndrome their defining features and recommended treatment, based on international guidelines, are shown in table 1. 


\section{TABLE 1 Criteria used to define the eight respiratory syndromes}

Syndrome
Fixed airflow limitation
(COPD) without
eosinophilia
Fixed airflow limitation
(COPD) with
eosinophilic
inflammation
Reversible airflow
limitation lasthma)

Other airflow limitation

Lower respiratory tract infection

Tuberculosis

Heart failure

Upper respiratory tract infection (common cold)

\section{Criteria}

Post-bronchodilator $\mathrm{FEV}_{1} / \mathrm{FVC}<$ lower

limit of normal AND no eosinophilia" at presentation

Post-bronchodilator $\mathrm{FEV}_{1} / \mathrm{FVC}<$ lower limit of normal AND eosinophilia ${ }^{\#}$ at presentation

$\mathrm{FEV}_{1}$ increases by $>200 \mathrm{~mL}$ and $>12 \%$ of the baseline value after inhaling a bronchodilator

$\mathrm{FEV}_{1} / \mathrm{FVC}<$ lower limit of normal on baseline spirometry for those without measure of post-bronchodilator spirometry

Focal or localised airspace consolidation on chest radiograph AND neutrophilia" Positive GeneXpert result for sputum sample

Cardiomegaly $^{+}$on chest radiograph AND one or more signs of pulmonary venous hypertension on chest radiograph $\mathrm{OR}$ elevated BNP/pro-BNP level $^{\S}$

Moderate symptoms in at least 2 of the 4 categories, OR mild symptoms in 3 or more categories, OR mild symptoms in one category plus a cough in Common Cold Questionnaire [28] with symptoms last $\leqslant 10$ days AND none of the above 7 syndromes
Treatment and management relevant to the analysis

Long-acting bronchodilators, SABA [29]

Long-acting bronchodilators, ICS, SABA [29]

ICS, long-acting bronchodilators [30]

May benefit from bronchodilators: consider post-bronchodilator spirometry

Antibiotics

Anti-tuberculosis agents

Diuretics for volume overload [31]

Symptomatic treatment

$\mathrm{FEV}_{1}$ : forced expiratory volume in $1 \mathrm{~s}$; FVC: forced vital capacity; SABA: short-acting beta-agonists; ICS: inhaled corticosteroids; BNP: brain natriuretic peptide. ${ }^{\#}$ : eosinophil count $>0.3 \times 10^{9} \mathrm{~L}^{-1}$ [29]; ๆ : neutrophil count $>6.3 \times 10^{9} \mathrm{~L}^{-1}[32]{ }^{+}$: cardiothoracic ratio $>0.55$; §: BNP level $>400 \mathrm{pg} \cdot \mathrm{mL}^{-1}$, pro-BNP level $>450 \mathrm{pg} \cdot \mathrm{mL}^{-1}$ for subjects aged $<50$ years, pro-BNP level $>900 \mathrm{pg} \cdot \mathrm{mL}^{-1}$ for subjects aged $50-75$ years, pro-BNP level $>1800 \mathrm{pg} \cdot \mathrm{mL}^{-1}$ for subjects aged $>75$ years [33].

\section{Statistical methods}

Prevalence estimates and associated 95\% confidence intervals were calculated for participants who completed the baseline survey. Patients with missing data or who were lost to follow-up were classified according to the data that were available. $\kappa$ statistics were used to evaluate the agreement between the pre-defined syndromes and the diagnostic labels given by healthcare workers at the facilities. Analyses were conducted using SAS (version 9.4; SAS Institute, Cary Corp., NC, USA). R Statistical Software (v.4.0.0, Foundation for Statistical Computing, Vienna, Austria) with UpSetR package [37] was used to visualise concurrences of syndromes in the participants.

\section{Ethical approval}

The study was approved by the Human Research Ethics Committee at the University of Sydney, and the Institutional Review Board of the Bach Mai Hospital, Hanoi, Vietnam.

\section{Results}

From September 2017 to October 2018, we screened 13157 patients for inclusion in the study (figure 1). Among 3163 patients who met the eligibility criteria, 1617 were randomly selected and invited to participate in the study. Following selection, 977 patients (including 878 outpatients and 99 inpatients) agreed and completed the baseline survey. Among them, 635 (65\%) had chest radiographs and 673 (68.9\%) had valid baseline spirometry. At the 4-week follow-up, 935 of 977 (95.7\%) patients completed the survey and 607 of 977 (62.1\%) performed valid spirometry.

The median age of the cohort was 59 years (interquartile range: 47-67 years). Nearly two-thirds were male, the majority of whom were current or ex-smokers (table 2). Only 6 of 325 (1.9\%) female patients 


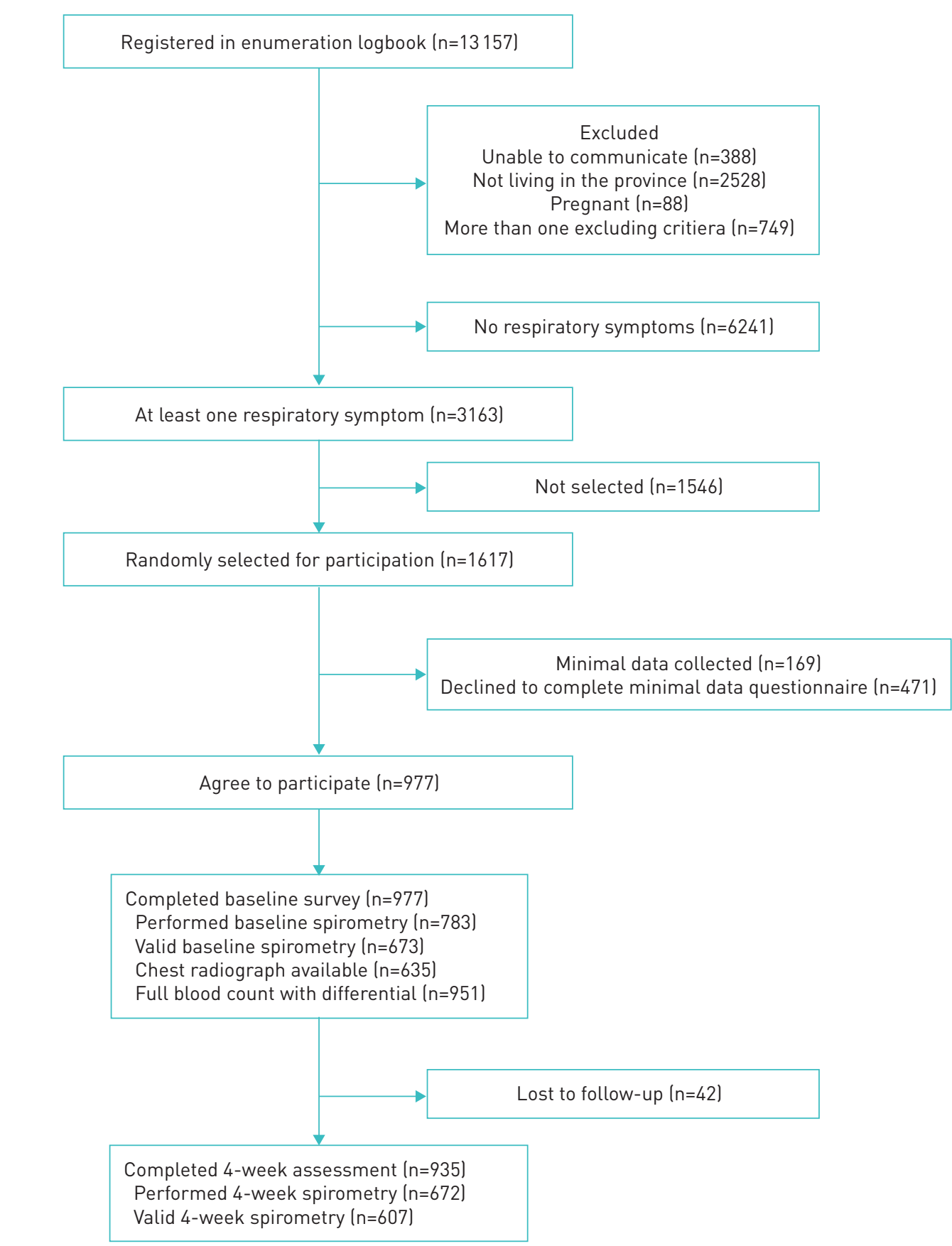

FIGURE 1 Consort diagram of participant recruitment.

were current or former smokers. Supplementary table S3 compares the demographic characteristics of participants and nonparticipants.

Table 3 shows the prevalence of the pre-defined syndromes in the study cohort. More than one in five of the cohort (198 of 977, 20.3\%) had fixed (post-bronchodilator) airflow limitation consistent with a diagnosis of COPD. Among these, 41.9\% (83 of 198) had associated peripheral blood eosinophilia. Only $2.7 \%$ of patients had reversible airflow limitation, consistent with asthma. Another $4.0 \%$ of participants exhibited airflow limitation on baseline spirometry but did not have a short-acting beta-agonist (SABA) administered so reversibility could not be assessed.

Findings consistent with LRTI and tuberculosis accounted for $8.4 \%$ and $1.4 \%$ of patients, respectively. Patients who had none of the above syndromes but who fitted the criteria for upper respiratory tract 


\begin{tabular}{|c|c|c|c|c|}
\hline & $\begin{array}{l}\text { All participants } \\
\text { (n=977) }\end{array}$ & $\begin{array}{l}\text { Central/provincial } \\
\text { facilities }(n=487)\end{array}$ & $\begin{array}{c}\text { District } \\
\text { facilities } \\
\text { (n=405) }\end{array}$ & $\begin{array}{c}\text { Commune } \\
\text { facilities }(n=85)\end{array}$ \\
\hline Age years & $59(47-67)$ & $57(42-66)$ & $60(50-67)$ & $61(52-68)$ \\
\hline Male sex & $643(65.8)$ & $333(68.4)$ & $250(61.7)$ & $60(70.6)$ \\
\hline Body mass index & $21.7(19.0-24.1)$ & $20.8(18.4-23.6)$ & $22.4(20.2-24.6)$ & $21.7(19.4-24.1)$ \\
\hline \multicolumn{5}{|l|}{ Highest education level" } \\
\hline Primary & $365(38.6)$ & 178 (38.5) & $156(39.0)$ & 31 (36.9) \\
\hline Secondary & $480(50.7)$ & $224(48.5)$ & $208(52.0)$ & $48(57.2)$ \\
\hline University & 92 (9.7) & 54 (11.7) & 33 (8.3) & $5(6.0)$ \\
\hline Unknown/no answer & $9(1.0)$ & $6(1.3)$ & $3(0.8)$ & $0(0.0)$ \\
\hline \multicolumn{5}{|l|}{ Comorbidity" } \\
\hline Heart disease & $150(15.9)$ & 80 (17.3) & $60(15.0)$ & 10 (11.9) \\
\hline Hypertension & $285(30.1)$ & $115(24.9)$ & $141(35.3)$ & $29(34.5)$ \\
\hline Diabetes & $74(7.8)$ & $36(7.8)$ & $30(7.5)$ & 8 (9.5) \\
\hline $\begin{array}{l}\text { Asthma, asthmatic } \\
\text { bronchitis or allergic } \\
\text { bronchitis }\end{array}$ & $142(15.0)$ & $73(15.8)$ & 55 (13.8) & $14(16.7)$ \\
\hline COPD & 93 (9.8) & 50 (10.8) & $38(9.5)$ & $5(6.0)$ \\
\hline Chronic bronchitis & $175(18.5)$ & $88(19.1)$ & $68(17.0)$ & $19(22.6)$ \\
\hline History of tuberculosis & $119(12.6)$ & $63(13.6)$ & $41(10.3)$ & 7 (8.3) \\
\hline \multicolumn{5}{|l|}{ Smoking history } \\
\hline \multicolumn{5}{|l|}{ Male } \\
\hline Current smoker & 318 (51.2) & $165(52.1)$ & $113(46.1)$ & 40 (67.8) \\
\hline Ex-smoker & $169(27.2)$ & $89(28.1)$ & $68(27.8)$ & 12 (20.3) \\
\hline Never smoked & $134(21.6)$ & 63 (19.9) & $64(26.1)$ & 7 (11.9) \\
\hline \multicolumn{5}{|l|}{ Female } \\
\hline Current smoker & $3(0.9)$ & $1(0.7)$ & $1(0.7)$ & $1(4.0)$ \\
\hline Ex-smoker & $3(0.9)$ & $2(1.4)$ & $1(0.7)$ & $0(0.0)$ \\
\hline Never smoked & $319(98.1)$ & $142(97.9)$ & 153 (98.7) & $24(96.0)$ \\
\hline \multicolumn{5}{|l|}{ Geographic region } \\
\hline Northern Vietnam & $568(58.1)$ & 321 (65.9) & $205(50.6)$ & 42 (49.4) \\
\hline Southern Vietnam & 409 (41.9) & 166 (34.1) & $200(49.4)$ & $43(50.6)$ \\
\hline
\end{tabular}

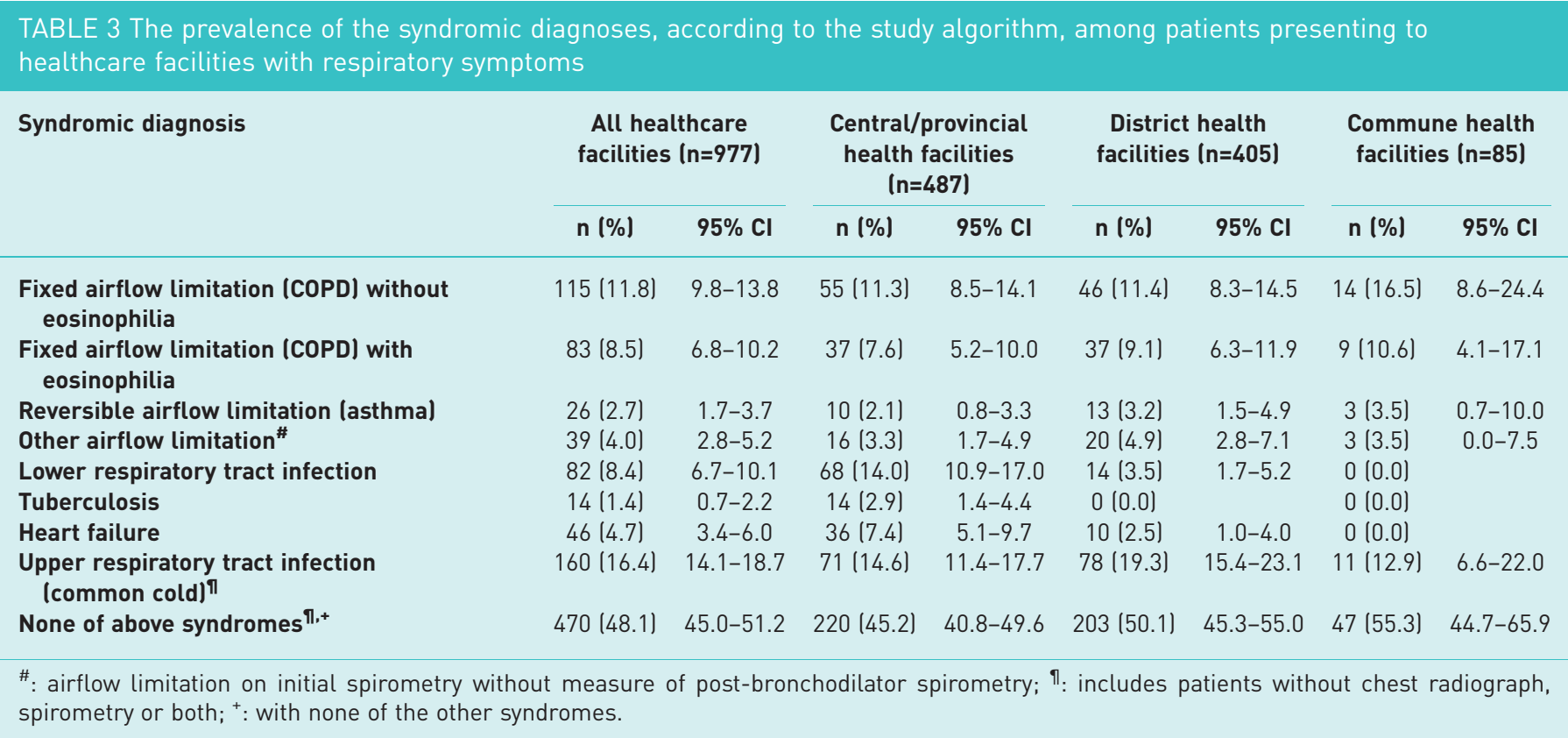




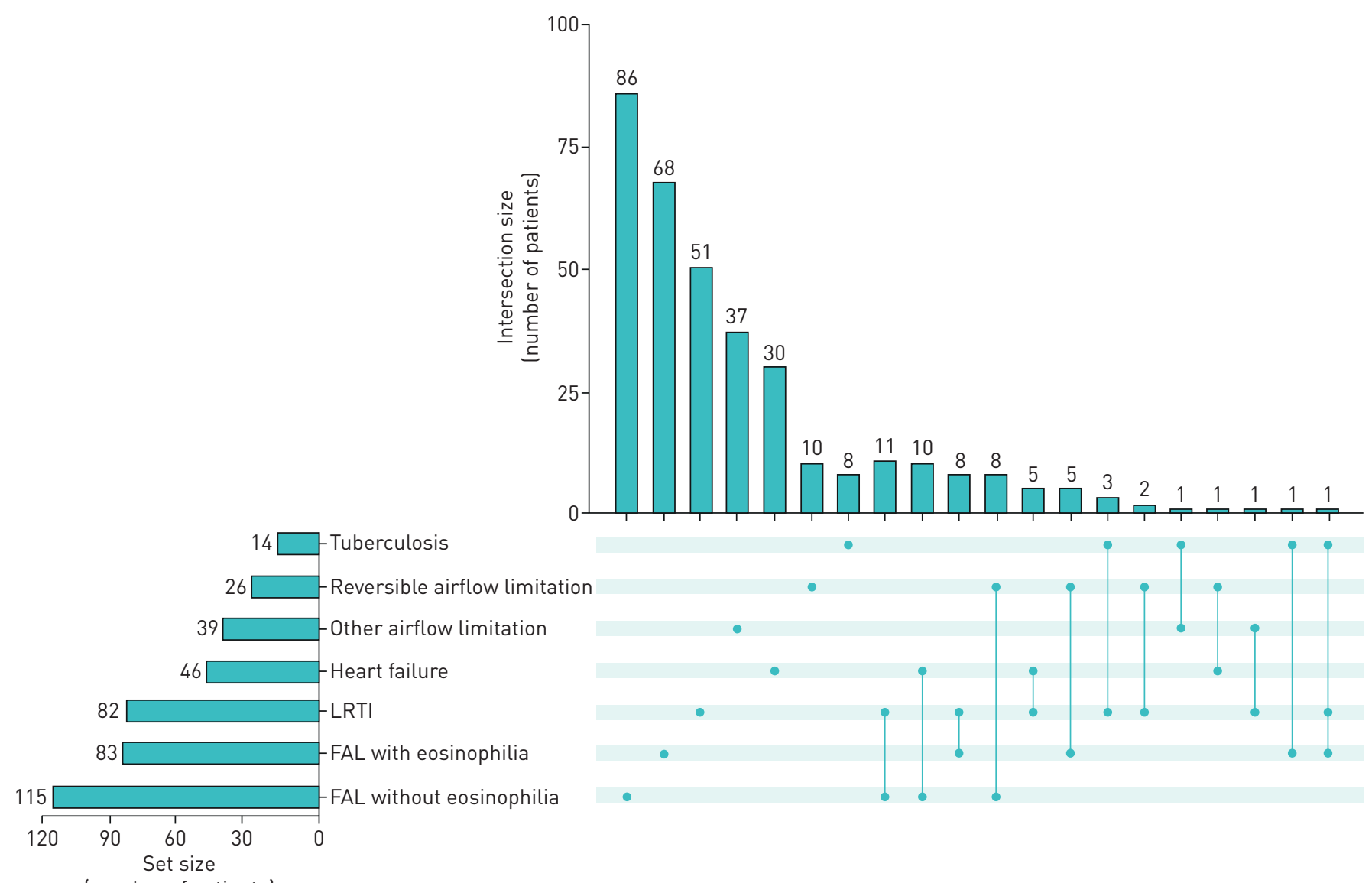

(number of patients)

FIGURE 2 Overlap of syndromes among enrolled participants with respiratory symptoms. The set size represents the number of patients with the syndrome next to it. The intersection size represents the number of patients with one (one dot) or more (connected dots) of the syndromes. For example, among 115 patients who had fixed airflow limitation (FAL) without eosinophilia, 86 had this syndrome alone and 11 also had lower respiratory tract infection (LRTI).

infection (URTI) constituted $16.4 \%$ of the sample and a further $48.1 \%$ of the cohort did not meet the criteria for any of the pre-defined syndromes.

\section{TABLE 4 Prevalence of syndromic diagnoses by age group}

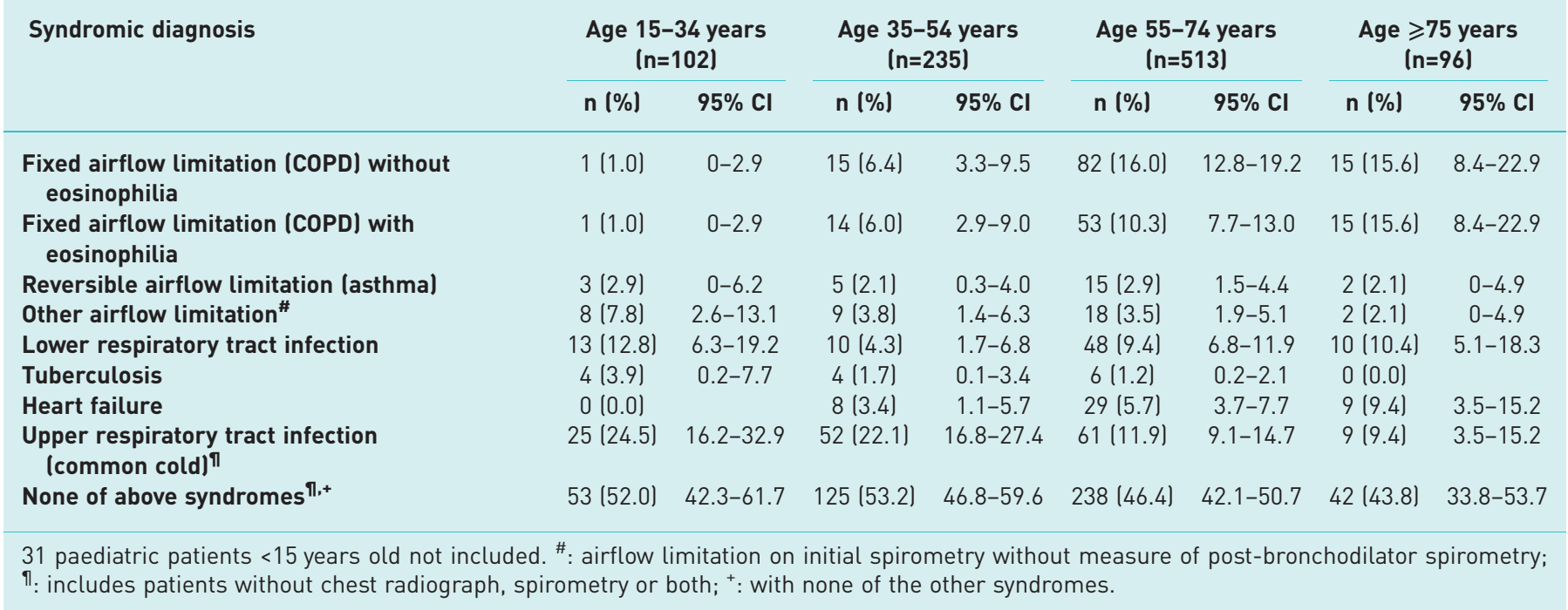


TABLE 5 The relationship between study-defined respiratory syndromes and diagnoses given by treating doctors

Syndromic diagnosis
Patients

Diagnoses by healthcare workers

COPD Asthma Pneumonia TB $\begin{gathered}\text { Heart } \\ \text { failure }\end{gathered}$ Bronchitis $\begin{gathered}\text { Common } \\ \text { cold }\end{gathered}$ None of

\section{All facilities}

Fixed airflow limitation (COPD) without eosinophilia

Fixed airflow limitation (COPD) with eosinophilia

Reversible airflow limitation (asthma) Other airflow limitation ${ }^{\#}$

Lower respiratory tract infection

Tuberculosis

Heart failure

Upper respiratory tract infection, common cold"

None of above syndromes ${ }^{\text {T1,+ }}$

\section{Central/provincial}

healthcare facilities

Fixed airflow limitation (COPD) without eosinophilia

Fixed airflow limitation (COPD) with eosinophilia

Reversible airflow limitation (asthma)

Other airflow limitation"

Lower respiratory tract infection

Tuberculosis

Heart failure

Upper respiratory tract infection, common cold?

None of above syndromes ${ }^{\text {I1,+ }}$

\section{District healthcare facilities}

Fixed airflow limitation (COPD) without eosinophilia

Fixed airflow limitation (COPD) with eosinophilia

Reversible airflow limitation (asthma) Other airflow limitation ${ }^{\#}$

Lower respiratory tract infection

Tuberculosis

Heart failure

Upper respiratory tract infection, common cold

None of above syndromes ${ }^{\text {Tl, }}+$

\section{Commune healthcare}

facilities

Fixed airflow limitation (COPD) without eosinophilia

\begin{tabular}{|c|c|c|c|c|c|c|c|}
\hline $40(34.8)$ & 19 (16.5) & 17 (14.8) & $3(2.6)$ & $0(0.0)$ & 33 (28.7) & $9(7.8)$ & 16 (13.9) \\
\hline $39(47.0)$ & 11 (13.3) & 7 (8.4) & $3(3.6)$ & $1(1.2)$ & 15 (18.7) & $4(4.8)$ & $15(18.1)$ \\
\hline 5 (19.2) & $6(23.1)$ & 2 (7.7) & $0(0.0)$ & 2 (7.7) & 7 (26.9) & 5 (19.2) & 5 (19.2) \\
\hline $3(7.7)$ & 7 (18.0) & $2(5.1)$ & $0(0.0)$ & $0(0.0)$ & $16(41.0)$ & 7 (18.0) & $10(25.6)$ \\
\hline $20(24.4)$ & $2(2.4)$ & $23(28.1)$ & $12(14.6)$ & 3 (3.7) & 16 (19.5) & $2(2.4)$ & $20(24.4)$ \\
\hline $1(7.1)$ & $0(0.0)$ & 5 (35.7) & $8(57.1)$ & $0(0.0)$ & $1(7.1)$ & $0(0.0)$ & $3(21.4)$ \\
\hline $14(30.4)$ & 7 (15.2) & 11 (23.9) & $3(6.5)$ & $5(10.9)$ & $12(26.1)$ & 4 (8.7) & 5 (10.9) \\
\hline 12 (7.5) & $13(8.1)$ & $7(4.4)$ & $5(3.1)$ & $1(0.6)$ & $56(35.0)$ & $57(35.6)$ & 27 (16.9) \\
\hline $50(10.6)$ & 40 (8.5) & $46(9.8)$ & $10(2.1)$ & $3(0.6)$ & 163 (34.7) & 65 (13.8) & $129(27.5)$ \\
\hline $21(38.2)$ & 12 (21.8) & 7 (12.7) & $2(3.6)$ & $0(0.0)$ & 17 (30.9) & $2(3.6)$ & $6(10.0)$ \\
\hline $23(62.2)$ & $3(8.1)$ & 5 (13.5) & $3(8.1)$ & $0(0.0)$ & $3(8.1)$ & $0(0.0)$ & 7 (18.9) \\
\hline 2 (20.0) & $2(20.0)$ & $1(10.0)$ & $0(0.0)$ & $2(20.0)$ & 2 (20.0) & $3(30.0)$ & 1 (10.0) \\
\hline $0(0.0)$ & 6 (37.5) & $1(6.3)$ & $0(0.0)$ & $0(0.0)$ & 4 (25.0) & $2(12.5)$ & 6 (37.5) \\
\hline 19 (27.9) & $1(1.5)$ & $21(30.9)$ & $11(16.2)$ & $3(4.4)$ & 9 (13.2) & 1 (1.5) & $18(26.5)$ \\
\hline $1(7.1)$ & $0(0.0)$ & 5 (35.7) & $8(57.1)$ & $0(0.0)$ & $1(7.1)$ & $0(0.0)$ & 3 (21.4) \\
\hline 13 (36.1) & 6 (16.7) & $11(30.6)$ & 3 (8.3) & $4(11.1)$ & 6 (16.7) & $0(0.0)$ & 4 (11.1) \\
\hline 9 (12.7) & 10 (14.1) & 2 (2.8) & $5(7.0)$ & $1(1.4)$ & 20 (28.2) & $16(22.5)$ & 15 (21.1) \\
\hline $33(15.0)$ & $33(15.0)$ & $31(14.1)$ & $10(4.6)$ & $2(0.9)$ & $51(23.2)$ & 16 (7.3) & $62(28.2)$ \\
\hline $18(39.1)$ & 7 (15.2) & $6(13.0)$ & $1(2.2)$ & $0(0.0)$ & $14(30.4)$ & 6 (13.0) & $4(8.7)$ \\
\hline $16(43.2)$ & 8 (21.6) & 1 (2.7) & $0(0.0)$ & $1(2.7)$ & 9 (24.3) & $4(10.8)$ & $3(8.1)$ \\
\hline $3(23.1)$ & $4(30.8)$ & 1 (7.7) & $0(0.0)$ & $0(0.0)$ & 5 (38.5) & 2 (15.4) & $1(7.7)$ \\
\hline 3 (15.0) & $1(5.0)$ & $1(5.0)$ & $0(0.0)$ & $0(0.0)$ & $11(55.0)$ & 5 (25.0) & 2 (20.0) \\
\hline $1(7.1)$ & $1(7.1)$ & $2(14.3)$ & $1(7.1)$ & $0(0.0)$ & 7 (50.0) & 1 (7.1) & 2 (14.3) \\
\hline 0 & & & & & & & \\
\hline $1(10)$ & $1(10)$ & $0(0.0)$ & $0(0.0)$ & $1(10)$ & $6(60)$ & $4(40)$ & 1 (10.0) \\
\hline 3 (3.9) & 3 (3.9) & $4(5.1)$ & $0(0.0)$ & $0(0.0)$ & 32 (41.0) & 38 (48.7) & 9 (11.5) \\
\hline $17(8.4)$ & $6(3.0)$ & 10 (4.9) & $0(0.0)$ & $1(0.5)$ & 96 (47.3) & 38 (18.7) & $49(24.1)$ \\
\hline $1(7.1)$ & $0(0.0)$ & $4(28.6)$ & $0(0.0)$ & $0(0.0)$ & 2 (14.3) & $1(7.1)$ & $6(42.9)$ \\
\hline
\end{tabular}

Continued 
TABLE 5 Continued

\begin{tabular}{|c|c|c|c|c|c|c|c|c|c|}
\hline Syndromic diagnosis & $\begin{array}{c}\text { Patients } \\
\mathbf{n}\end{array}$ & \multicolumn{8}{|c|}{ Diagnoses by healthcare workers } \\
\hline $\begin{array}{l}\text { Reversible airflow } \\
\text { limitation (asthma) }\end{array}$ & 3 & $0(0.0)$ & $0(0.0)$ & $0(0.0)$ & $0(0.0)$ & $0(0.0)$ & $0(0.0)$ & $0(0.0)$ & $3(100.0)$ \\
\hline Tuberculosis & 0 & & & & & & & & \\
\hline Heart failure & 0 & & & & & & & & \\
\hline $\begin{array}{l}\text { Upper respiratory tract } \\
\text { infection, common cold" }\end{array}$ & 11 & $0(0.0)$ & $0(0.0)$ & $1(9.1)$ & $0(0.0)$ & $0(0.0)$ & $4(36.4)$ & $3(27.3)$ & $3(27.3)$ \\
\hline $\begin{array}{l}\text { None of above } \\
\text { syndromes }\end{array}$ & 47 & $0(0.0)$ & $1(2.1)$ & $5(10.6)$ & $0(0.0)$ & $0(0.0)$ & $16(34.0)$ & $11(23.4)$ & 18 (38.3) \\
\hline
\end{tabular}

Among the 977 participants, 56 (5.7\%) met the criteria for two concurrent syndromes. Another one patient $(0.1 \%)$ met the criteria for three syndromes concurrently. Figure 2 shows the numbers of patients with one or more of the syndromes. The most common combination of syndromes were 1) fixed airflow limitation without eosinophilia and a LRTI (11 patients), and 2) fixed airflow limitation without eosinophilia and heart failure (10 patients).

The prevalence of fixed airflow limitation and heart failure increased with age (table 4). By contrast, patients presenting with URTI and those whose symptoms could not be attributed to any pre-defined syndrome were more likely to be young people.

Among 115 patients with fixed airflow limitation and no eosinophilia, only $34.8 \%$ were diagnosed with COPD by treating doctors (table 5). Only one of 14 (7.1\%) patients with fixed airflow limitation assessed at the commune health centres was correctly diagnosed with COPD. Overall, the agreement between the presence of fixed airflow limitation (with or without eosinophilia) and a clinician diagnosis of COPD was poor ( $\kappa=0.31,95 \%$ CI: $0.23-0.38$ ). The agreement between the presence of reversible airflow limitation and a clinical diagnosis of asthma was even worse $(\kappa=0.16$; 95\% CI: $0.08-0.25)$. Agreement was also poor for the diagnoses of LRTI $(\kappa=0.32$; 95\% CI: $0.15-0.49)$, tuberculosis $(\kappa=0.06 ; 95 \% \mathrm{CI}:-0.01-0.13)$, and heart failure ( $\kappa=0.15$; 95\% CI: 0.02-0.28). Among 630 patients with URTI or none of the syndromes, 173 (27.5\%) received at least one diagnostic label for a disease for which drug therapy would be indicated, including COPD, asthma, heart failure, pneumonia, and tuberculosis. The clinical diagnoses for the 129 patients with none of the syndromes who were given none of the relevant labels are provided in supplementary table S4.

Table 6 shows the proportions of patients with each syndrome who were prescribed medications during their attendance at the healthcare facilities. Less than half of patients with fixed airflow limitation were given long-acting bronchodilators (85 of 198, 42.9\%) and a minority of patients with either reversible airflow obstruction or fixed airflow obstruction with eosinophilia were prescribed inhaled corticosteroids (30 of 109, 27.5\%). No patients attending commune health centres were prescribed maintenance inhaled medicines and only 1 out 26 patients with fixed or reversible airflow limitation received a SABA inhaler. Table 6 also shows that antibiotics were prescribed to more than half of the patients, even among those with syndromes for which this treatment is unlikely to be beneficial, such as those with only common cold and patients with none of the defined syndromes. The proportion of patients prescribed an antibiotic was similar across all facilities.

\section{Discussion}

In the study we applied a syndromic approach to assess the diagnosis and treatment provided across all levels of the Vietnamese healthcare system. We showed that many people presenting to healthcare facilities with respiratory symptoms had either no defined respiratory syndrome or had only URTI. Furthermore, 
TABLE 6 Treatment provided to patients with the syndromic diagnoses

\begin{tabular}{|c|c|c|c|c|c|c|c|c|}
\hline $\begin{array}{l}\text { Syndromic } \\
\text { diagnosis }\end{array}$ & $\begin{array}{c}\text { Patients } \\
\mathrm{n}\end{array}$ & $\begin{array}{c}\text { Systemic } \\
\text { corticosteroids }\end{array}$ & $\begin{array}{l}\text { Inhaled } \\
\text { corticosteroids }\end{array}$ & $\begin{array}{l}\text { Long-acting } \\
\text { bronchodilators }\end{array}$ & $\begin{array}{c}\text { Short-acting } \\
\beta \text {-agonist }\end{array}$ & Antibiotics & Antituberculosis & Diuretics \\
\hline \multicolumn{9}{|l|}{ All facilities } \\
\hline $\begin{array}{l}\text { Reversible } \\
\text { airflow } \\
\text { limitation } \\
\text { (asthma) }\end{array}$ & 26 & $8(30.8)$ & $5(19.2)$ & 7 (26.9) & 1 (3.9) & 16 (61.5) & $0(0.0)$ & 3 (11.5) \\
\hline $\begin{array}{l}\text { Other airflow } \\
\text { limitation" }\end{array}$ & 39 & $7(18.0)$ & $7(18.0)$ & 8 (20.5) & $2(5.1)$ & 20 (51.3) & $0(0.0)$ & $0(0.0)$ \\
\hline Heart failure & 46 & 21 (45.7) & 11 (23.9) & $15(32.6)$ & 7 (15.2) & 32 (70.0) & $0(0.0)$ & $12(26.1)$ \\
\hline $\begin{array}{l}\text { Upper respiratory } \\
\text { tract infection, } \\
\text { common cold }\end{array}$ & 160 & 50 (31.3) & $18(11.3)$ & $28(17.5)$ & $8(5.0)$ & $104(65.0)$ & $2(1.3)$ & $0(0.0)$ \\
\hline $\begin{array}{l}\text { None of above } \\
\text { syndromes }\end{array}$ & 470 & $113(24.0)$ & $62(13.2)$ & $91(19.4)$ & $24(5.1)$ & 271 (57.7) & $4(0.9)$ & $21(4.5)$ \\
\hline Overall & 977 & $283(29.0)$ & $161(16.5)$ & $235(24.1)$ & $66(6.8)$ & $586(60.0)$ & 10 (1.0) & $49(5.0)$ \\
\hline \multicolumn{9}{|l|}{$\begin{array}{l}\text { Central/provincial } \\
\text { healthcare } \\
\text { facilities }\end{array}$} \\
\hline $\begin{array}{l}\text { Fixed airflow } \\
\text { limitation } \\
\text { (COPD) without } \\
\text { eosinophilia }\end{array}$ & 55 & $28(50.9)$ & $24(43.6)$ & $26(47.3)$ & 6 (10.9) & 37 (67.3) & $0(0.0)$ & $3(5.5)$ \\
\hline $\begin{array}{l}\text { Other airflow } \\
\text { limitation }\end{array}$ & 16 & 2 (12.5) & 6 (37.5) & 5 (31.3) & $1(6.3)$ & $7(43.8)$ & $0(0.0)$ & $0(0.0)$ \\
\hline $\begin{array}{l}\text { Lower respiratory } \\
\text { tract infection }\end{array}$ & 68 & 26 (38.2) & $18(26.5)$ & $20(29.4)$ & $1(1.5)$ & $41(60.3)$ & $1(1.5)$ & $5(7.4)$ \\
\hline Tuberculosis & 14 & $1(7.1)$ & $1(7.1)$ & $0(0.0)$ & $0(0.0)$ & $6(42.9)$ & 3 (21.4) & $0(0.0)$ \\
\hline Heart failure & 36 & $16(44.4)$ & $10(27.8)$ & 14 (38.9) & $6(16.7)$ & $24(66.7)$ & $0(0.0)$ & $11(30.6)$ \\
\hline $\begin{array}{l}\text { Upper respiratory } \\
\text { tract infection, } \\
\text { common cold }\end{array}$ & 71 & $23(32.4)$ & $14(19.7)$ & $17(23.9)$ & $6(8.5)$ & $42(59.2)$ & $2(2.8)$ & $0(0.0)$ \\
\hline $\begin{array}{l}\text { None of above } \\
\text { syndromes }\end{array}$ & 220 & $51(23.2)$ & $54(24.6)$ & $58(26.4)$ & $20(9.1)$ & $121(55.0)$ & $3(1.4)$ & $13(5.9)$ \\
\hline Overall & 487 & $151(31.0)$ & $134(27.5)$ & 145 (29.8) & $41(8.4)$ & $283(58.1)$ & $8(1.6)$ & 33 (6.8) \\
\hline \multicolumn{9}{|l|}{$\begin{array}{l}\text { District healthcare } \\
\text { facilities }\end{array}$} \\
\hline $\begin{array}{l}\text { Fixed airflow } \\
\text { limitation } \\
\text { [COPD] } \\
\text { without } \\
\text { eosinophilia }\end{array}$ & 46 & $14(30.4)$ & $6(13.0)$ & $22(47.8)$ & 10 (21.7) & $27(58.7)$ & $0(0.0)$ & $2(4.4)$ \\
\hline
\end{tabular}


TABLE 6 Continued

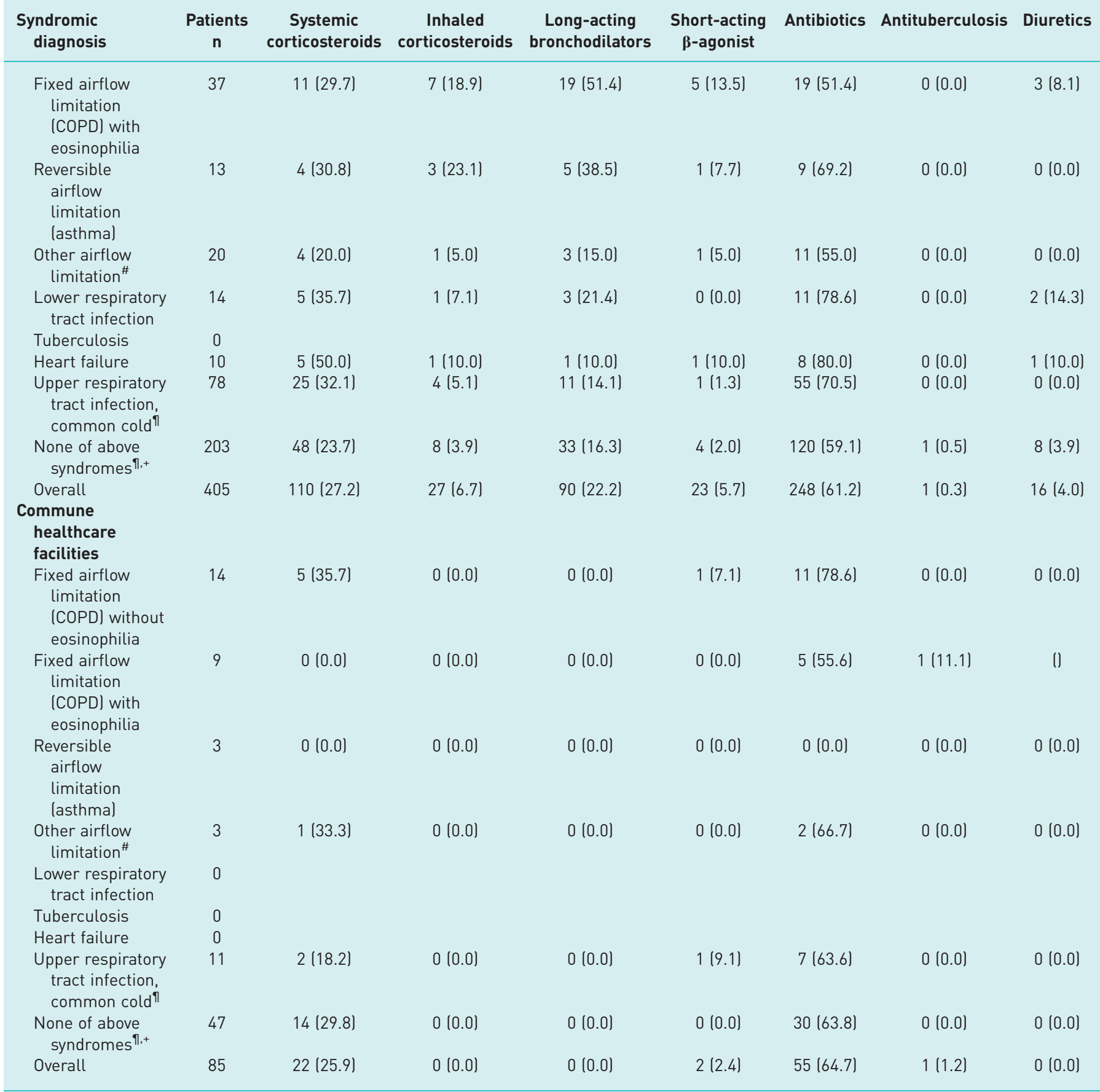

Data are presented as $\mathrm{n}(\%)$ unless otherwise stated. ": airflow limitation on initial spirometry without measure of post-bronchodilator

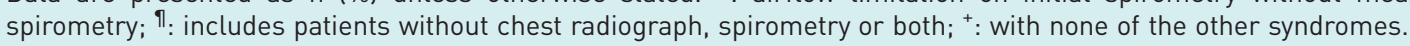

those who did have well-defined syndromes, such as fixed or reversible airflow limitation, a LRTI, tuberculosis or heart failure were often not diagnosed with the condition at the facility. The use of specific therapies, such as inhaled medicines and antibiotics, were poorly correlated with the presence of the relevant syndrome.

The agreement between the syndromic diagnosis that we made based on a simple, standardised assessment and the diagnostic label applied by the attending clinicians was poor. This highlights the importance of 
utilising simple tests, particularly spirometry, to facilitate accurate diagnosis at all levels of the health system.

The benefit of applying a standardised diagnostic approach extends from diagnosing disease to appropriate prescription of treatment. The proportion of patients with fixed airflow limitation given inhaled long-acting bronchodilators and the proportion of patients with reversible airflow limitation given inhaled corticosteroids were both low. This is consistent with a recent cross-sectional survey that revealed a low level of knowledge and implementation of the Global Initiative for Asthma guidelines 2015 among primary care physicians in Vietnam [16]. Using spirometry to obtain evidence of airflow obstruction would more likely result in the appropriate targeted pharmacotherapy being given to patients [38].

In contrast to the under-use of inhaled medicines, inappropriate prescription of antibiotics and systemic corticosteroids occurred at all levels of facilities. We found that a substantial proportion of patients with a URTI, or with no defined respiratory syndrome, were provided with antibiotics. The use of systemic corticosteroids might be justified by the presence of exacerbation of COPD or asthma in some patients. However, the proportion of patients given corticosteroids was high even among patients without evidence of airflow limitation.

Our findings give rise to important questions that can be addressed by future studies. The findings of poor correlation between pre-defined syndromes and the diagnosis and treatment applied by the treating doctors, indicate that implementing a syndromic approach may improve patient care. The syndromic approach is of the most value where the capacity to implement a complex diagnostic algorithm is limited, such as within community healthcare facilities. An optimal syndromic pathway to diagnosis and management must also balance the needs and capacity of the local system in each setting. Secondly, given the difficulties in obtaining inhaled medicines and maintaining follow-up for chronic respiratory diseases in resource-limited settings, tailored pragmatic interventions coupling with the syndromic approach need to be considered. Following the introduction of an intervention, the approach can also be used to evaluate the impact of the intervention.

This approach provides a simple assessment of burden of respiratory diseases and will ensure an acceptable quality of patient care, while allowing for health-system barriers to diagnosis and treatment decisions. The approach can be adapted for other LMICs. Further studies are necessary to demonstrate the benefits of applying such approaches in different clinical settings.

This study has a number of strengths. We enrolled a randomly selected representative sample of patients at all four levels of health facilities in four provinces of Vietnam. This allows us to generalise our findings to urban and rural settings across Vietnam. Secondly, we defined the syndromes independently of the treating clinicians using a simple, standardised algorithmic approach. This allowed us to evaluate the diagnostic decision-making and evaluate the appropriateness of treatment against objective criteria.

There were several limitations. First, diagnostic tests, such as spirometry and chest radiography were not available for all participants. A minority of patients did not have a spirometry result of acceptable quality. For these patients a definite syndromic diagnosis could not be made. Second, some patients with asthma may had a normal spirometry result and a negative bronchodilator response upon presentation. This may explain the low prevalence of asthma observed in our study. Finally, the study sample may slightly under-represent the proportion of patients attending commune level facilities, in comparison to higher level facilities [39].

In conclusion, this study identified a substantial discordance between standardised syndromic diagnoses of respiratory disease and the diagnoses reached within the health system in Vietnam. Increased access to spirometry, and possibly other objective measures, including radiology and biomarkers, may assist in the implementation of locally relevant syndromic approaches to management. This would be an important element of strategies for reducing the burden of chronic lung disease in resource-limited settings.

Conflict of interest: W-C. Huang has nothing to disclose. G.J. Fox has nothing to disclose. N.Y. Pham has nothing to disclose. T.A. Nguyen has nothing to disclose. V.G. Vu has nothing to disclose. Q.C. Ngo has nothing to disclose. V.N. Nguyen has nothing to disclose. S. Jan has nothing to disclose. J. Negin reports grants from the Global Alliance for Chronic Diseases during the conduct of the study. T.T.L. Le has nothing to disclose. G.B. Marks reports funds for research paid to his institution by and participation in an expert panel for AstraZeneca, and funds for research paid to his institution by GSK, outside the submitted work.

Support statement: This work was supported by a project grant funded through the Australian National Health and Medical Research Council (NHMRC) (APP1116020) in collaboration with the Global Alliance for Chronic Disease. W-C. Huang was supported by the University International Postgraduate Award funded by the University of New South Wales. G.J. Fox was supported by a NHMRC Career Development Fellowship (APP1148372). The funders had no role in the study design, data collection, data analysis, writing of the report, or the decision to submit the article for publication. Funding information for this article has been deposited with the Crossref Funder Registry. 


\section{References}

1 Ottmani S-E, Scherpbier R, Pio A, et al. Practical Approach to Lung Health (PAL): a Primary Health Care Strategy for the Integrated Management of Respiratory Conditions in People Five Years of Age and Over. www.apps.who.int/iris/handle/10665/69035 Date last accessed: April 28, 2020. Date last updated: 2005.

2 Forum of International Respiratory Societies. The Global Impact of Respiratory Disease. 3rd Edn. Sheffield, European Respiratory Society, 2017.

3 Institute for Health Metrics and Evaluation. Global Health Data Exchange. www.ghdx.healthdata.org/ gbd-results-tool Date last accessed: April 28, 2020.

4 Troeger C, Blacker B, Khalil IA, et al. Estimates of the global, regional, and national morbidity, mortality, and aetiologies of lower respiratory infections in 195 countries, 1990-2016: a systematic analysis for the Global Burden of Disease Study 2016. Lancet Infect Dis 2018; 18: 1191-1210.

5 Lamprecht B, Mahringer A, Soriano JB, et al. Is spirometry properly used to diagnose COPD? Results from the BOLD study in Salzburg, Austria: a population-based analytical study. Prim Care Respir J 2013; 22: 195-200.

6 Zwar NA, Marks GB, Hermiz O, et al. Predictors of accuracy of diagnosis of chronic obstructive pulmonary disease in general practice. Med J Aust 2011; 195: 168-171.

7 Danielsson P, Olafsdottir IS, Benediktsdottir B, et al. The prevalence of chronic obstructive pulmonary disease in Uppsala, Sweden--the Burden of Obstructive Lung Disease (BOLD) study: cross-sectional population-based study. Clin Respir J 2012; 6: 120-127.

8 Toelle BG, Xuan W, Bird TE, et al. Respiratory symptoms and illness in older Australians: the Burden of Obstructive Lung Disease (BOLD) study. Med J Aust 2013; 198: 144-148.

9 Pascoe S, Locantore N, Dransfield MT, et al. Blood eosinophil counts, exacerbations, and response to the addition of inhaled fluticasone furoate to vilanterol in patients with chronic obstructive pulmonary disease: a secondary analysis of data from two parallel randomised controlled trials. Lancet Respir Med 2015; 3: 435-442.

10 Bafadhel M, Peterson S, De Blas MA, et al. Predictors of exacerbation risk and response to budesonide in patients with chronic obstructive pulmonary disease: a post-hoc analysis of three randomised trials. Lancet Respir Med 2018; 6: 117-126.

11 Yang IA, Clarke MS, Sim EH, et al. Inhaled corticosteroids for stable chronic obstructive pulmonary disease. Cochrane Database Syst Rev 2012; 7: Cd002991.

12 Pavord ID, Lettis S, Anzueto A, et al. Blood eosinophil count and pneumonia risk in patients with chronic obstructive pulmonary disease: a patient-level meta-analysis. Lancet Respir Med 2016; 4: 731-741.

13 Pavord ID, Beasley R, Agusti A, et al. After asthma: redefining airways diseases. Lancet 2018; 391: 350-400.

14 Barnes NC, Sharma R, Lettis $\mathrm{S}$, et al. Blood eosinophils as a marker of response to inhaled corticosteroids in COPD. Eur Respir J 2016; 47: 1374-1382.

15 Miao R, Wan C, Wang Z, et al. Inappropriate antibiotic prescriptions among pediatric inpatients in different type hospitals. Medicine (Baltimore) 2020; 99: e18714-e18714.

16 Nguyen VN, Nguyen QN, Le An P, et al. Implementation of GINA guidelines in asthma management by primary care physicians in Vietnam. Int J Gen Med 2017; 10: 347-355.

17 Sharif R, Cuevas CR, Wang Y, et al. Guideline adherence in management of stable chronic obstructive pulmonary disease. Respir Med 2013; 107: 1046-1052.

18 Tamblyn R, Ernst P, Winslade N, et al. Evaluating the impact of an integrated computer-based decision support with person-centered analytics for the management of asthma in primary care: a randomized controlled trial. $J$ Am Med Inform Assoc 2015; 22: 773-783.

19 McDonagh MS, Peterson K, Winthrop K, et al. Interventions to reduce inappropriate prescribing of antibiotics for acute respiratory tract infections: summary and update of a systematic review. J Int Med Res 2018; 46: 3337-3357.

20 Godman B, Haque M, McKimm J, et al. Ongoing strategies to improve the management of upper respiratory tract infections and reduce inappropriate antibiotic use particularly among lower and middle-income countries: findings and implications for the future. Curr Med Res Opin 2020; 36: 301-327.

21 Hamzaoui A, Ottmani S-E. Practical approach to lung health: lung health for everyone? Eur Respir Rev 2012; 21 : 186-195.

22 English RG, Bateman ED, Zwarenstein MF, et al. Development of a South African integrated syndromic respiratory disease guideline for primary care. Prim Care Respir J 2008; 17: 156-163.

23 Banda HT, Mortimer K, Bello GA, et al. Informal health provider and practical approach to lung health interventions to improve the detection of chronic airways disease and tuberculosis at primary care level in Malawi: study protocol for a randomised controlled trial. Trials 2015; 16: 576.

24 Banda $\mathrm{H}$, Robinson $\mathrm{R}$, Thomson $\mathrm{R}$, et al. The 'practical approach to lung health' in sub-Saharan Africa: a systematic review. Int J Tuberc Lung Dis 2016; 20: 552-559.

25 Brimkulov N, Ottmani SE, Pio A, et al. Feasibility test results of the practical approach to lung health in Bishkek, Kyrgyzstan. Int J Tuberc Lung Dis 2009; 13: 533-539.

26 Thi HC, Thu PP, Van GV, et al. Late-breaking abstract: knowledge, attitudes and practice of medical doctors in diagnosis and management of COPD patients in Vietnam. Eur Respir J 2014; 44: Suppl. 58, 4412.

27 Thu TA, Rahman M, Coffin S, et al. Antibiotic use in Vietnamese hospitals: A multicenter point-prevalence study. Am J Infect Control 2012; 40: 840-844.

28 Powell H, Smart J, Wood LG, et al. Validity of the common cold questionnaire (CCQ) in asthma exacerbations. PLoS ONE 2008; 3: e1802.

29 Global Initiative for Chronic Obstructive Lung Disease. Global Strategy for the Diagnosis, Management, and Prevention of Chronic Obstructive Pulmonary Disease, 2020. www.goldcopd.org/ Date last accessed: April 28, 2020. Date last updated: 2020.

30 Global Initiative for Asthma. Global Strategy for Asthma Management and Prevention, 2020. www.ginasthma.org/ Date last accessed: April 28, 2020. Date last updated: 2020.

31 Yancy CW, Jessup M, Bozkurt B, et al. 2017 ACC/AHA/HFSA Focused Update of the 2013 ACCF/AHA Guideline for the Management of Heart Failure: a Report of the American College of Cardiology/American Heart Association Task Force on Clinical Practice Guidelines and the Heart Failure Society of America. J Am Coll Cardiol 2017; 70: 776-803. 
32 Wu X, Zhao M, Pan B, et al. Complete blood count reference intervals for healthy Han Chinese adults. PLoS ONE 2015; 10: e0119669.

33 Chow SL, Maisel AS, Anand I, et al. Role of biomarkers for the prevention, assessment, and management of heart failure: a scientific statement from the American Heart Association. Circulation 2017; 135: e1054-e1091.

34 Miller MR, Hankinson J, Brusasco V, et al. Standardisation of spirometry. Eur Respir J 2005; 26: 319-338.

35 Ferguson GT, Enright PL, Buist AS, et al. Office spirometry for lung health assessment in adults: a consensus statement from the National Lung Health Education Program. Chest 2000; 117: 1146-1161.

36 Quanjer PH, Stanojevic S, Cole TJ, et al. Multi-ethnic reference values for spirometry for the 3-95-yr age range: the global lung function 2012 equations. Eur Respir J 2012; 40: 1324-1343.

37 Conway JR, Lex A, Gehlenborg N. UpSetR: an R package for the visualization of intersecting sets and their properties. Bioinformatics 2017; 33: 2938-2940.

38 Gibson PG, McDonald VM, Marks GB. Asthma in older adults. Lancet 2010; 376: 803-813.

39 General Statistics Office of Vietnam. Vietnam Household Living Standards Survey 2012. www.gso.gov.vn/ default_en.aspx?tabid=483\&idmid=4\&ItemID=13888 Date last accessed April 16, 2020. 